\title{
PN1a Stage Finding
}

National Cancer Institute

\section{Source}

National Cancer Institute. pN1a Stage Finding. NCI Thesaurus. Code C48747.

A clinical and/or pathologic regional lymph nodes TNM finding usually indicating the presence of metastasis in one to three regional lymph nodes. 